\title{
Suppression of tumor growth via IGFBP3 depletion as a potential treatment in glioma
}

\author{
${ }^{*}$ Chia-Hua Chen, PhD, ${ }^{1,2}$ Pin-Yuan Chen, MD, PhD, ${ }^{1,5}$ You-Yu Lin, PhD, ${ }^{6}$ Li-Ying Feng, BS, 1,2 \\ Shin-Han Chen, MSc, ${ }^{5}$ Chia-Yuan Chen, MSc, ${ }^{4}$ Yin-Cheng Huang, MD, PhD, ${ }^{2}$ \\ Chiung-Yin Huang, PhD, ${ }^{1,2}$ Shih-Ming Jung, MD, ${ }^{3}$ Leslie Y. Chen, PhD, ${ }^{4}$ and Kuo-Chen Wei, MD ${ }^{1,2}$
}

${ }^{1}$ School of Medicine, Chang Gung University, Taoyuan; Departments of ${ }^{2}$ Neurosurgery, ${ }^{3}$ Pathology, and ${ }^{4}$ Medical Research and Development, Chang Gung Memorial Hospital, Linkou Medical Center, Taoyuan; ${ }^{5}$ Department of Neurosurgery, Keelung Chang Gung Memorial Hospital, Keelung; and ${ }^{6}$ Graduate Institute of Clinical Medicine, National Taiwan University College of Medicine, Taipei, Taiwan

OBJECTIVE Despite intensive medical treatment, patients with glioblastoma (grade IV glioma [GBM]) have a low 5-year survival rate of $5.5 \%$. In this study, the authors tried to improve currently used therapies by identification of a therapeutic target, IGFBP3, for glioma treatment.

METHODS IGFBP3 RNA expression in 135 patients newly diagnosed with glioma was correlated with clinicopathological factors. Immunohistochemical analysis was performed to determine IGFBP3 protein expression in glioma specimens. The effect of IGFBP3 depletion on cell proliferation was examined using IGFBP3 knockdown glioma cells. Intracranial infusion of IGFBP3 siRNAs was performed to evaluate the effect of IGFBP3 depletion in mouse intracranial xenograft models.

RESULTS We demonstrated higher IGFBP3 expression in GBM than in tumor margin and grade II glioma. IGFBP3 expression was not only positively correlated with tumor grades but also associated with tumor histology and IDH1/2 mutation status. Additionally, higher IGFBP3 expression predicted shorter overall survival in glioma and GBM proneural subgroup patients. In vitro cell culture studies suggested IGFBP3 knockdown suppressed cell proliferation and induced cell cycle $G_{2} / M$ arrest as well as apoptosis in glioma cells. Also, accumulation of DNA double-strand breaks and $\gamma \mathrm{H} 2 \mathrm{AX}$ was observed in IGFBP3 knockdown cells. IGFBP3 knockdown delayed in vivo tumor growth in mouse subcutaneous xenograft models. Furthermore, convection-enhanced delivery of IGFBP3 siRNA to mouse brain suppressed intracranial tumor growth and prolonged survival of tumor-bearing mice.

CONCLUSIONS Our findings suggest IGFBP3 predicts poor outcome of glioma patients and is a potential therapeutic target for which depletion of its expression suppresses tumor growth through inducing apoptosis and accumulation of DNA damage in glioma cells.

https://thejns.org/doi/abs/10.3171/2018.8.JNS181217

KEYWORDS glioma; IGFBP3; apoptosis; DNA damage; targeted therapy; therapeutic siRNA; oncology

$\mathrm{G}$ LIOMAS originate from glial cells of the central nervous system and account for $80.7 \%$ of all malignant brain tumors diagnosed in the United States. ${ }^{19}$ High-grade gliomas, especially grade IV glioma (glioblastoma [GBM]), are intractable; the estimated 5-year sur- vival rate of patients suffering from GBM is $5.5 \%$, and the median survival after recurrence is only 5-7 months. ${ }^{19}$ Current glioma therapies mainly comprise surgical resection and radiation combined with temozolomide. ${ }^{21}$ However, outcomes for GBM patients are still poor because of

ABBREVIATIONS DSB = double-strand break; EGFR = epidermal growth factor receptor; FBS = fetal bovine serum; FITC = fluorescein isothiocyanate; GBM = glioblastoma (grade IV glioma); IDH1/2 = isocitrate dehydrogenase 1/2; IGF = insulin-like growth factor; IGFBP3 = IGF binding protein-3; IGF1R = IGF-1 receptor; PARP = poly (ADP-ribose) polymerase; $\mathrm{PCR}=$ polymerase chain reaction; $\mathrm{PI}=$ propidium iodide; REMBRANDT = Repository of Molecular Brain Neoplasia Data; siCtrl = control siRNA; S1P = sphingosine-1 phosphate; TCGA = The Cancer Genome Atlas; WB = Western blot.

SUBMITTED May 2, 2018. ACCEPTED August 16, 2018.

INCLUDE WHEN CITING Published online January 11, 2019; DOI: 10.3171/2018.8.JNS181217.

${ }^{*}$ C.H.C. and K.C.W. contributed equally to this article. P.Y.C. and Y.Y.L. contributed equally to this article. 
resistance to chemotherapy and the lack of efficient therapeutic drugs. Genome sequencing of GBM identified several grouping and prognostic factors, such as $1 \mathrm{p} / 19 \mathrm{q}$ codeletion and isocitrate dehydrogenase 1/2 (IDH1/2), which are associated with patient survival and sensitivity to chemotherapy. ${ }^{3,513}$ Further investigations of the correlation between molecular changes and disease progression are required to develop new therapeutic targets for improvement of glioma treatment.

Insulin-like growth factor binding protein-3 (IGFBP3) is a member of the insulin-like growth factor (IGF) binding protein family. ${ }^{1}$ It was first identified as a binding partner of IGFs for stabilizing the IGFs in blood and an inhibitor of IGF-1 receptor (IGF1R) signaling by blocking IGF binding to receptors in tissues. ${ }^{2}$ Overexpression of IGFBP 3 is found in renal clear cell carcinomas, ${ }^{23}$ head and neck squamous cancers ${ }_{1}^{15}$ pancreatic ductal adenocarcinomas, ${ }^{29}$ and aggressive breast cancers, ${ }^{17}$ and its expression is associated with poor patient outcome. IGFBP3 functions as a tumor promoter by enhancing cell growth through increasing sphingosine kinase-1 (SphK1) expression and sphingosine-1 phosphate (S1P) formation, which transactivates epidermal growth factor receptor (EGFR) or IGF1R signaling pathways. ${ }^{17}$ Although aberrant IGFBP3 expression is common among cancers and a great effort has been made to elucidate its function, its role in cancer progression is intricate and requires further study.

IGFBP3 expression dysregulation has also been observed in GBM; however, its contribution to glioma progression is not well understood.22 In the present study, IGFBP3 knockdown suppressed tumor growth by inducing DNA double-strand break (DSB) accumulation and apoptosis in glioma cells. Also, delayed cell growth was observed in mouse subcutaneous xenografts from IGFBP3 knockdown cells. The treatment efficacy of IGFBP3 knockdown on brain tumor was demonstrated by intracranial infusion of IGFBP3 siRNAs, which significantly prolonged the survival of brain-tumor-bearing mice. Our findings suggest that IGFBP3 regulates cell proliferation and tumor growth and is a potential therapeutic target in treating glioma.

\section{Methods}

\section{Patients and Tissue Samples}

Tissue samples were collected from 193 patients newly diagnosed with glioma, who received treatment at the Linkou Chang Gung Memorial Hospital, Taiwan, between February 2004 and December 2015. Patient sample collection and usage were approved by the Chang Gung Medical Foundation Institutional Review Board (107-0014C1 and 104-9960B); written consent was obtained from patients prior to sample collection. Tumor pathology was determined based on examination of H\&E-stained sections under a light microscope and the presence of $1 \mathrm{p} / 19 \mathrm{q}$ codeletion. Details of tissue collection and patient information are listed in the Supplementary Information.

\section{cDNA Synthesis and Quantitative Polymerase Chain Reaction}

Total RNA was collected using TRIzol reagent (In- vitrogen) and extracted using an miRNeasy Mini Kit (Qiagen) according to the manufacturer's protocol. Cell line cDNA was synthesized using SuperScript III FirstStrand Synthesis SuperMix (Invitrogen), whereas tissue RNA was converted to cDNA using a High-Capacity RNA-to-cDNA kit (Applied Biosystems). Gene expression was quantified using TaqMan gene expression assays (IGFBP3: Hs00365742_gland ACTB: Hs99999903_m1; Applied Biosystems) or LightCycler 480 SYBR Green I Master assays (Roche) using the LightCycler 480 Instrument II (Roche).

\section{Immunohistochemical Analysis}

Tissue sections were deparaffinized in xylene and rehydrated in a series of diluted alcohols. Tissue slides were then immersed in boiled Epitope Retrieval Solution $\mathrm{pH}$ 6 (Novocastra) for 10 minutes. Immunohistochemical staining was performed using the UltraVision Quanto Detection System HRP DAB (Thermo Fisher) according to the manufacturer's protocol. Sections were incubated with a rabbit polyclonal anti-IGFBP3 antibody (sc-9028, Santa Cruz) or a mouse monoclonal anti-CD31 antibody (ab28364, abcam) at 1:100 in 1\% bovine serum albumin (BSA)/phosphate-buffered saline (PBS) at room temperature for 1 hour. All sections were counterstained with hematoxylin (Sigma) and mounted with mounting medium. The anti-IGFBP3 antibody was replaced by a control rabbit polycloncal $\operatorname{IgG}$ in the negative control staining. IGFBP 3 expression was categorized into 4 groups $(+0,+1$, +2 , and +3 ) according to the expression percentage and intensity in glioma tumor cells. The blood vessel number and area were counted and measured using Image J $1.48 \mathrm{v}$ (National Institutes of Health).

\section{IDH1/2 Mutation Detection}

Tumor DNA was extracted and subjected to polymerase chain reaction (PCR) for amplification of a 481-base-pair (bp) fragment containing IDHI codon 132 and a 290-bp fragment containing $I D H 2$ codon 172 . PCR products were then sequenced to determine their $I D H 1 / 2$ status. Further details are listed in the Supplementary Information.

\section{Cell Culture}

U-87 MG, U-118 MG, A172, and LN229 cell lines were purchased from the American Type Culture Collection and maintained in DMEM (Gibco). DBTRG-05MG cells were purchased from the Bioresource Collection and Research Center (Hsinchu, Taiwan) and maintained in RPMI 1640 (Gibco). U-87 MG/Luc cells were kindly provided by the Brain Tumor Center (University of California, San Francisco, CA) and maintained in DMEM with $1 \times$ non-essential amino acid (NEAA) solution (Gibco). GBM primary cells (WK-802, WK-909, WK-935, and WK-958) were derived from fresh tumor tissues of patients with GBM who underwent brain tumor surgery at the Linkou Chang Gung Memorial Hospital, Taiwan, and were cultured in DMEM-F12 (Gibco). The growth medium contained 10\% fetal bovine serum (FBS) (Gibco), $100 \mathrm{IU} / \mathrm{ml}$ penicillin, and $100 \mu \mathrm{g} / \mathrm{ml}$ streptomycin (Gibco), and cells were cultured in a humidified tissue culture incubator at 
$37^{\circ} \mathrm{C}$ and $5 \% \mathrm{CO}_{2}$ atmosphere. Information regarding cell authentication and Mycoplasma detection is listed in the Supplementary Information.

\section{Knockdown of IGFBP3 in Glioma Cells}

IGFBP3 shRNAs (shIBP3-1: TRCN0000286844; shIBP3-2: TRCN0000286764) or a control vector (shCtrl: pLKO_TRC025) was delivered into cells using a lentivirus-based infection system. Packaged lentiviruses were purchased from the National RNAi Core Facility at Academia Sinica in Taiwan. Infected cells were selected using puromycin for 3 days before further analysis. Stealth siRNAs against IGFBP3 (siIBP3-1: HSS105267; siIBP3-2: HSS179813) and nontargeting control siRNA (siCtrl) were purchased from Invitrogen. U-87 MG/Luc cells were transfected with siRNAs using Lipofectamine RNAiMAX (Invitrogen) at a final concentration of $10 \mathrm{nM}$ for 48 hours prior to experiments.

\section{Antibodies}

Antibodies against IGFBP3 (sc-9028) and $\beta$-actin (sc47778) were purchased from Santa Cruz Biotechnology. Anti-caspase-3, anti-poly (ADP-ribose) polymerase (antiPARP), and anti- $\gamma \mathrm{H} 2 \mathrm{AX}$ antibodies were purchased from Cell Signaling Technology.

\section{Trypan Blue Exclusion Assay}

Cells were seeded in 24-well plates in triplicate at a density of 8000 cells/well. Viable cells were analyzed using trypan blue exclusion assay on days 2 and 4 .

\section{In Vivo Subcutaneous Tumor Growth}

Five-week-old male NOD-SCID mice (BioLASCO, Taiwan) with body weights ranging from 23 to $26 \mathrm{~g}$ were subcutaneously injected with $100 \mu \mathrm{l}$ Matrigel (Corning) containing $5 \times 10^{6}$ tumor cells. Tumor sizes and the weights of the mice were measured twice a week. Mice were euthanized 24 and 28 days after U-87 MG and U-118 MG implantation, respectively, and tumors were excised for further analysis. Animal experiments were approved by the Institutional Animal Care and Use Committee of Chang Gung University (CGU15-180).

\section{Cell Cycle Analysis}

Cells were serum starved for 24 hours; the medium was replaced with growth medium for 12 and 24 hours. Cells were collected for DNA staining using propidium iodide (PI), and DNA content was analyzed by using a BD FACSCalibur Flow Cytometry System (BD Biosciences) and ModFit LT 4.1 software (Verity Software House).

\section{Cell Apoptosis Detection}

Cells were serum starved as previously described in Cell Cycle Analysis and then freshly collected and stained for early apoptosis markers using a fluorescein isothiocyanate (FITC) annexin V apoptosis detection kit (BD Biosciences) according to the manufacturer's instructions. Annexin V and PI staining were measured using a flow cytometer and analyzed using FlowJo v7.6. For late apoptosis detection, whole-cell lysates were collected and the levels of cleaved caspase- 3 and cleaved PARP protein were determined by Western blot (WB).

\section{Comet Assay}

Intracellular DNA damage was measured using the Comet Assay Kit (Trevigen) according to the manufacturer's instructions. Single-cell gel electrophoresis was performed using alkaline electrophoresis solution for detecting single-/double-strand DNA breaks. DNA was stained with 4',6-diamidino-2-phenylindole (DAPI) and images were taken using a fluorescence microscope (Leica DM2500). DNA damage was assessed using CASPLab 1.2.2 and presented as average tail moments from at least 200 cells per group.

\section{Effects of IGFBP3 siRNA on In Vivo Mouse Xenograft Models}

Five-week-old male nude mice (BioLASCO) were intracranially injected with $5 \times 10^{5} \mathrm{U}-87 \mathrm{MG} / \mathrm{Luc}$ cells in 5 $\mu l$ of growth medium. The tumor cell injection was performed at the position $0.5 \mathrm{~mm}$ to the right of the bregma, $2.5 \mathrm{~mm}$ posterior to the bregma, and $4 \mathrm{~mm}$ below the skull surface. Control or IGFBP3 siRNAs of $1.5 \mu \mathrm{g} /$ mouse were mixed with in vivo jetPEI transfection reagent (Polyplustransfection) according to the manufacturer's instruction and infused into tumors using the convection-enhanced delivery (CED) method. Briefly, mice were anesthetized with inhalational anesthetic isoflurane (Forane, AbbVie Limited) and placed on a mouse stereotaxic instrument with continuous supplement of isoflurane. CED procedures were performed with a UMP3 microinjection system (UMC4 pump controller and UMP3 pump, World Precision Instruments) and a 100- $\mu$ l NANOFIL-100 syringe (World Precision Instruments) with a 26G needle at an infusion rate of $1 \mu \mathrm{l} / \mathrm{min}$. After infusion of $5 \mu \mathrm{l} \mathrm{siRNA}$ and in vivo jetPEI mixture, the cannula was left in the tissue for 10 minutes to prevent reflux. The weights of the mice and tumor sizes, determined by the Xenogen IVIS 100 In Vivo Imaging System, were measured twice a week. Mice were euthanized when they lost $20 \%$ weight or became weak and unable to perform normal living functions. The brains of mice were excised for further analyses.

\section{Statistical Analysis}

Measurements were repeated at least 3 times; data are presented as mean \pm standard deviation unless otherwise described. All statistical analyses were performed using GraphPad Prism 5 (GraphPad Software Inc.). One- or twoway ANOVA with Bonferroni or Dunnett's posttest was used to compare differences between the experimental groups. Fisher's exact test and Pearson's chi-square test were used to assess the correlation between pairs of categorical variables. Survival probabilities were estimated using the Kaplan-Meier method; the differences between groups were analyzed using log-rank tests. Each factor possibly affecting patient survival was further analyzed by univariate and multivariate Cox proportional hazard model. All statistical tests were two-tailed; $p<0.05$ was considered statistically significant. 

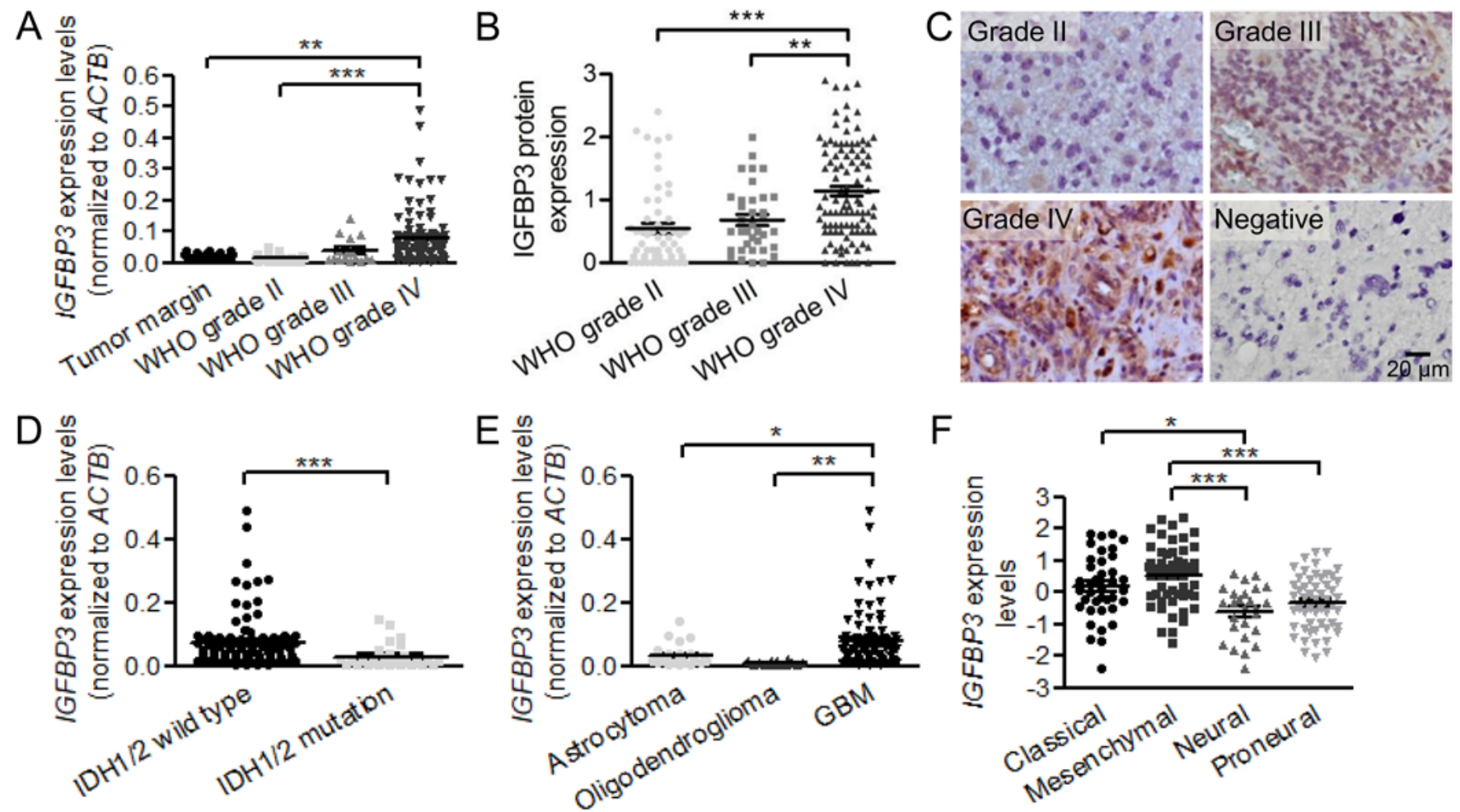

FIG. 1. IGFBP3 expression levels in glioma tissues and its correlation with clinicopathological factors. A: IGFBP3 RNA expression in tumor margin and tumors of different grades. B: IGFBP3 protein expression in tissue specimens from patients with newly diagnosed grade II $(n=56)$, III $(n=36)$, and IV $(G B M)(n=100)$ glioma. C: Representative images of IGFBP3 protein expression in different grades of glioma specimens. D and E: IGFBP3 RNA expression in tumors of different IDH1/2 status (D) and histology (E). F: IGFBP3 expression in tumors of 4 GBM subgroups from the TCGA patient cohort. Each point represents the IGFBP3 RNA level of a single patient. Error bars represent \pm SEM. ${ }^{*} p<0.05 ;{ }^{* *} p<0.01 ;{ }^{* * *} p<0.001$.

\section{Results \\ IGFBP3 Expression and Correlation With Glioma Clinicopathological Factors}

We examined IGFBP3 RNA and protein expression in newly diagnosed gliomas using quantitative PCR and immunohistochemical analysis, respectively. GBMs had the highest IGFBP3 RNA expression among gliomas, and the expression was significantly higher in GBM than in tumor margin and grade II tumor tissue samples (Fig. 1A). Similar results were observed for IGFBP3 protein expression in different grades of glioma tissues (Fig. 1B and C). For analyzing the correlation between IGFBP 3 expression and glioma clinicopathological factors, the median IGFBP3 expression level was used as a cut point for categorizing the glioma patients into "IGFBP3 low" and "IGFBP3 high" groups. Our results showed that IGFBP3 RNA expression was positively correlated with glioma grade and associated with histology and $I D H 1 / 2$ mutation (Table 1). No significant correlation was observed between IGFBP3 RNA expression and age, sex, tumor laterality, or extent of resection. A lower IGFBP3 expression was observed in IDH1/2 mutated tumors compared with wild type tumors ( $\mathrm{p}<0.0001$; Fig. 1D). Among different histological types, the highest IGFBP3 expression was observed in GBM (Fig. $1 \mathrm{E})$. The expression difference of IGFBP3 between astrocytoma and oligodendroglioma was not significant, prob- ably due to the small sample size. When we separated the grade II/III tumors into the IGFBP3 low and the IGFBP3 high groups, a significant difference of $I G F B P 3$ expression was observed between astrocytoma and oligodendroglioma specimens (chi-square test, $\mathrm{p}=0.0149$; Supplementary Table S1). GBM can be further classified into 4 subgroups derived from distinct neural cell types. ${ }^{25}$ By analyzing the GBM RNA profiles from The Cancer Genome Atlas (TCGA) database, ${ }^{25}$ we found that GBM IGFBP3 expression was lower in oligodendroglial lineage tumors, including the neural and proneural GBM subgroups, than in the GBM tumors from the astroglial lineage that is the mesenchymal subgroup (Fig. 1F). These data support the association between IGFBP3 RNA expression and glioma histology. Overall, our results are consistent with those of previous reports stating that IGFBP3 is upregulated in GBM, further suggesting that IGFBP3 expression is associated with glioma grade, histology, and IDHI/2 mutations.

\section{Higher IGFBP3 RNA Expression Correlated to Shorter Overall Survival in Glioma}

Correlation of IGFBP3 RNA expression and overall survival of newly diagnosed glioma patients was analyzed using our patient cohort and the Repository of Molecular Brain Neoplasia Data (REMBRANDT) database. ${ }^{8}$ Newly diagnosed glioma patients with high IGFBP3 expression levels had shorter overall survival than patients with low 
IGFBP3 expression levels $(\mathrm{n}=132, \log$-rank, $\mathrm{p}=0.0126$; Fig. 2A). Similar results were observed in a patient cohort from the REMBRANDT database $(\mathrm{n}=329$, log-rank, $\mathrm{p}<0.0001$; Fig. 2B). However, the overall survival was not significantly different between the IGFBP3 high and $I G F B P 3$ low patients with newly diagnosed GBM in our patient cohort (log-rank, $\mathrm{p}=0.5842$; Fig. $2 \mathrm{C}$ ), though minor differences were observed in patients from the REMBRANDT and TCGA GBM databases (Supplementary Fig. 1). Furthermore, univariate analysis showed that, in addition to IGFBP3 expression, patient age at diagnosis, glioma grade, and IDHI/2 mutation correlated with overall survival, whereas with the use of multivariate analysis, only tumor grade was an independent predictor of patient survival (Table 2). In the TCGA GBM dataset, higher $I G F B P 3$ expression correlated with shorter overall surviv$\mathrm{al}$ in the proneural GBM subgroup (log-rank, $\mathrm{p}=0.0045$; Fig. 2D) but not in other 3 subgroups.

\section{IGFBP3 Knockdown Suppressed Cell Growth and Induced $\mathrm{G}_{2} / \mathrm{M}$ Cell Cycle Arrest in Glioma Cells}

To evaluate the effect of IGFBP3 expression on cell growth, we depleted IGFBP3 expression in glioma cells using IGFBP3 shRNA and analyzed cell proliferation and cell cycle progression. IGFBP3 was differentially expressed in 5 glioma cell lines and 4 GBM primary cells (Fig. 3A). U-87 MG and U-118 MG cells showed higher IGFBP3 expression and were selected for further investigation into IGFBP3 function. WBs were performed to validate the knockdown efficiency of the IGFBP3 shRNAs (Fig. 3B). Morphology of IGFBP3 knockdown cells was larger and more flatten than that of control cells (Fig. 3C). IGFBP3 knockdown suppressed cell proliferation, as determined by trypan blue exclusion assays (Fig. 3D). The growth-suppressing effects of IGFBP3 knockdown were also observed in other glioma cell lines and primary cells (Supplementary Fig. 2). Cell cycle analysis with flow cytometry and PI showed that around $80 \%$ of control cells were in the $\mathrm{G}_{0} / \mathrm{G}_{1}$ phase, whereas the number of cells in the $\mathrm{G}_{2} / \mathrm{M}$ phase was 3 times greater in the IGFBP3 knockdown group than in the control group (Fig. 3E and F). Additionally, the results of BrdU pulse labeling showed a significant increase in the $\mathrm{G}_{2} / \mathrm{M}$ phase and a decrease in the $\mathrm{S}$ phase in the IGFBP3 knockdown group (Supplementary Fig. 3). These data suggested that IGFBP3 knockdown significantly reduced cell growth and induced cell cycle arrest in glioma cells.

\section{IGFBP3 Knockdown Induced Apoptosis and Accumulation of DNA Damage in Glioma Cells}

In addition to the cell cycle arrest at the $\mathrm{G}_{2} / \mathrm{M}$ phase, we observed an increase in cell apoptosis in IGFBP3 knockdown cells. The percentage of apoptotic (annexin V+/PI-) and dead (annexin $\mathrm{V}+/ \mathrm{PI}+$ ) cells was increased 2-fold in the IGFBP3 knockdown group (Fig. 4A). The expression of late apoptosis indicators, cleaved caspase-3 and cleaved PARP, was also increased in IGFBP3 knockdown cells (Fig. 4B). As cell cycle arrest at the $\mathrm{G}_{2} / \mathrm{M}$ phase followed by cell apoptosis and death is a general phenomenon of cells in response to DNA damage, ${ }^{27,31}$ we next examined
TABLE 1. IGFBP3 RNA expression and clinicopathologic characteristics of newly diagnosed glioma

\begin{tabular}{|c|c|c|c|c|}
\hline \multirow[b]{2}{*}{ Characteristics } & \multirow{2}{*}{$\begin{array}{c}\text { No. of Pts } \\
(n=134)\end{array}$} & \multicolumn{2}{|c|}{ IGFBP3 Expression } & \multirow[b]{2}{*}{$p$ Value } \\
\hline & & Low & High & \\
\hline \multicolumn{5}{|l|}{ Age in yrs } \\
\hline$<50$ & 57 & $32(56.1)$ & $25(43.9)$ & $0.2944 \dagger$ \\
\hline$\geq 50$ & 77 & $35(45.5)$ & $42(54.5)$ & \\
\hline \multicolumn{5}{|l|}{ Sex } \\
\hline Male & 82 & $39(47.6)$ & $43(52.4)$ & $0.5951 \dagger$ \\
\hline Female & 52 & $28(53.8)$ & $24(46.2)$ & \\
\hline \multicolumn{5}{|l|}{ Grade } \\
\hline$\|$ & 22 & $20(90.9)$ & $2(9.1)$ & $<0.0001^{*} \ddagger$ \\
\hline III & 17 & $10(58.8)$ & $7(41.2)$ & \\
\hline IV & 95 & $37(38.9)$ & $58(61.1)$ & \\
\hline \multicolumn{5}{|l|}{ Histology } \\
\hline Astrocytoma & 25 & $16(64.0)$ & $9(36.0)$ & $<0.0001^{*} \ddagger$ \\
\hline Oligodendroglioma & 14 & $14(100.0)$ & $0(0.0)$ & \\
\hline GBM & 95 & $37(38.9)$ & $58(61.1)$ & \\
\hline \multicolumn{5}{|l|}{ IDH1/2 status } \\
\hline Wild type & 98 & $41(41.8)$ & $57(58.2)$ & $0.0015^{\star} \dagger$ \\
\hline Mutant & 29 & $22(75.9)$ & $7(24.1)$ & \\
\hline \multicolumn{5}{|l|}{ Laterality } \\
\hline Left & 51 & $25(49.0)$ & $26(51.0)$ & $0.4376 \ddagger$ \\
\hline Right & 69 & $37(53.6)$ & $32(46.4)$ & \\
\hline Bilateral & 12 & $5(41.7)$ & $7(58.3)$ & \\
\hline Middle & 2 & $0(0.0)$ & $2(100.0)$ & \\
\hline \multicolumn{5}{|l|}{ Resection extent } \\
\hline Gross total & 32 & $13(40.6)$ & $19(59.4)$ & $0.2035 \dagger$ \\
\hline Subtotal & 72 & $40(55.6)$ & $32(44.4)$ & \\
\hline
\end{tabular}

Pts = patients

Values are numbers of patients (\%) unless stated otherwise.

${ }^{*}$ Significant $(p<0.05)$.

$\dagger$ Fisher's exact test.

$\ddagger$ Chi-square test.

whether IGFBP3 knockdown induced DNA damage in glioma cells. The alkaline comet assay showed higher tail moments in IGFBP3 knockdown cells than in control cells (Fig. 4C). The number of $\gamma \mathrm{H} 2 \mathrm{AX}$ foci, a DSB marker, also increased in IGFBP3 knockdown cells (Fig. 4D). Taken together, our results indicated that IGFBP3 knockdown induced cell apoptosis and the accumulation of DSB and $\gamma \mathrm{H} 2 \mathrm{AX}$, which may have resulted in the death of glioma cells.

\section{IGFBP3 Knockdown Suppressed Tumor Growth in Mouse Subcutaneous Xenograft Models}

To evaluate the effect of IGFBP3 knockdown on in vivo cell growth, mouse subcutaneous xenograft models were performed using IGFBP3 knockdown or control cells. In the in vivo mouse subcutaneous models, IGFBP3 knockdown glioma cells showed delayed tumor growth (U-87 MG, Fig. 5A; U-118 MG, Fig. 5C) and decreased tumor weight (U-87 MG, Fig. 5B; U-118 MG, Fig. 5D), except for U-87 MG/shIBP3-2. Blood vessels in tumors were stained 


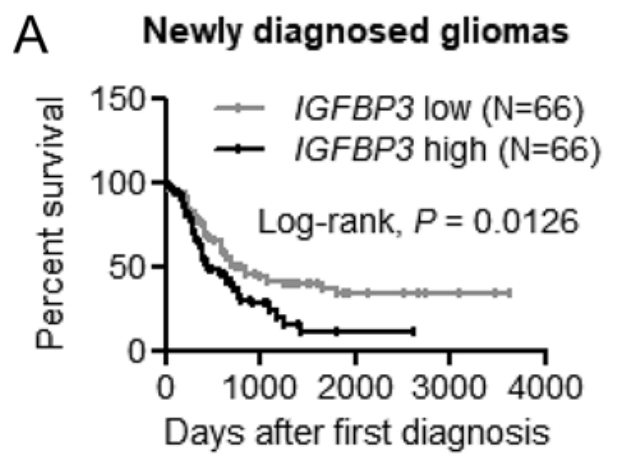

C Newly diagnosed glioblastoma

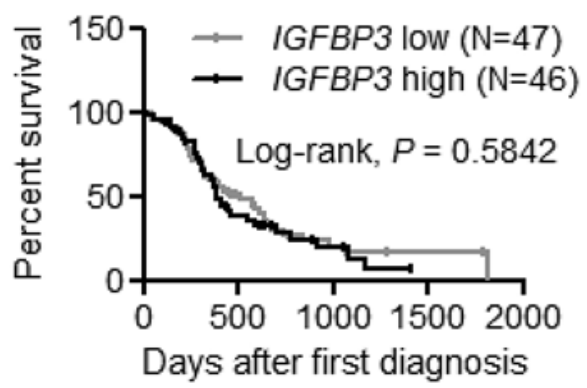

\section{B Glioma: REMBRANDT}
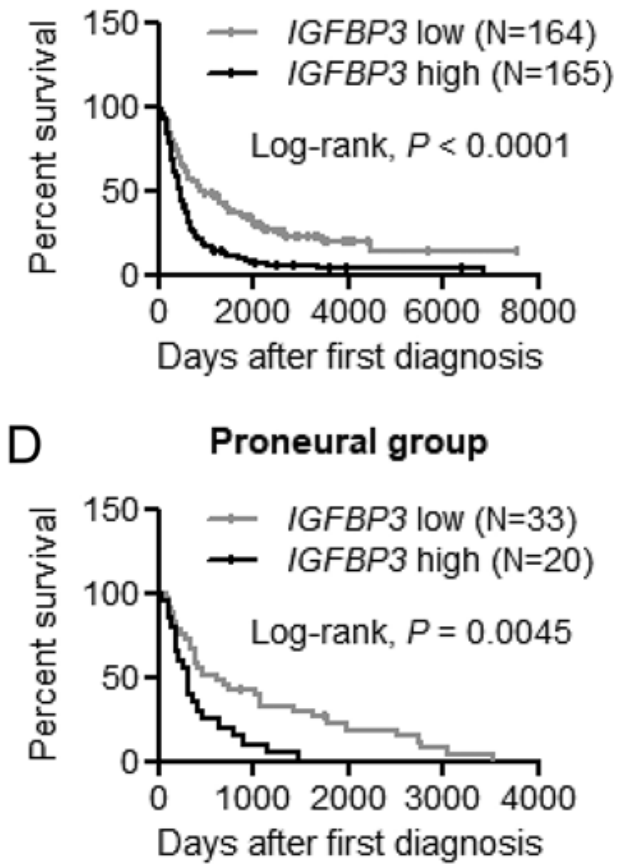

FIG. 2. The correlation of IGFBP3 expression with overall survival of newly diagnosed glioma and GBM patients. A and B: Overall survival of newly diagnosed glioma patients from our patient cohort $(A)$ and the REMBRANDT database $(B)$ with high or low IGFBP3 expression. C: Overall survival of newly diagnosed GBM patients with high or low IGFBP3 expression from our patient cohort. D: Overall survival of the GBM proneural subgroup with high or low IGFBP3 expression from the TCGA database.

by an antibody against mouse CD31 and the number and coverage of blood vessels were calculated (Fig. 5E). IGFBP3 knockdown reduced the blood vessel coverage area in mouse subcutaneous xenografts of U-87 MG and U-118 MG (Fig. 5F), whereas the blood vessel number was decreased only in tumors derived from IGFBP3 knockdown U-118 MG cells compared with control cells (Fig. $5 \mathrm{G})$. These findings indicated that IGFBP3 knockdown in glioma cells significantly suppressed in vivo cell growth and tumor formation.

\section{IGFBP3 Depletion Suppresses Tumor Growth and}

\section{Prolongs Survival in Mouse Intracranial Xenograft Models}

To test whether depletion of IGFBP3 could be a potential therapy for gliomas, two different IGFBP3 siRNAs were infused into mouse intracranial tumors generated using U-87 MG/Luc. Both siRNAs could efficiently suppress in vitro cell growth of U-87 MG/Luc (Fig. 6A). Five days after the implantation of U-87 MG/Luc, IGFBP3 or scram- ble control siRNA (siCtrl) was packaged and infused into mouse intracranial tumors using CED (Fig. 6B). Infusion of two different IGFBP3 siRNAs (siIBP3-1 and siIBP3-2) delayed tumor growth in the brains of the mice and the tumors were smaller in IGFBP3 siRNA-treated mice compared with control mice at day 25 after implantation (Fig. $6 \mathrm{C}$ ). Compared with day 4 , by day 25 , tumor volumes increased 23-fold, 10-fold, and 2-fold in siCtrl-, siIBP3-1-, and siIBP3-2-infused mice, respectively (Fig. 6D and E). $I G F B P 3$ siRNA-treated mice showed better overall survival compared with siCtrl-treated mice $(p=0.0259$, logrank test), and the median survival of siCtrl-, siIBP3-1-, and silBP3-2-treated mice was 25, 32, and 35 days, respectively (Fig. 6F). These results indicated that IGFBP3 siRNA could significantly suppress tumor growth and prolong survival in mouse intracranial xenograft models.

\section{Discussion}

As tumor categorization of glioma has long been con-

TABLE 2. Univariate and multivariate Cox regression analysis of prognostic factors and IGFBP3 expression in glioma

\begin{tabular}{|c|c|c|c|c|c|c|}
\hline \multirow[b]{2}{*}{ Variable } & \multicolumn{3}{|c|}{ Univariate } & \multicolumn{3}{|c|}{ Multivariate } \\
\hline & $\mathrm{HR}$ & $95 \% \mathrm{Cl}$ & p Value & $\mathrm{HR}$ & $95 \% \mathrm{Cl}$ & $p$ Value \\
\hline Age at diagnosis & 1.026 & $1.011-1.041$ & 0.0007 & 1.008 & $0.9922-1.024$ & 0.3205 \\
\hline Glioma grade II, III, or IV & 2.76 & $1.883-4.046$ & $<0.0001$ & 2.337 & $1.504-3.630$ & 0.000159 \\
\hline IGFBP3 expression & 13.97 & $1.524-128.1$ & 0.0197 & 1.223 & $0.09159-16.330$ & 0.879 \\
\hline IDH1/2 mutation & 0.2507 & $0.1267-0.4963$ & $<0.0001$ & 0.669 & $0.2891-1.548$ & 0.3475 \\
\hline
\end{tabular}



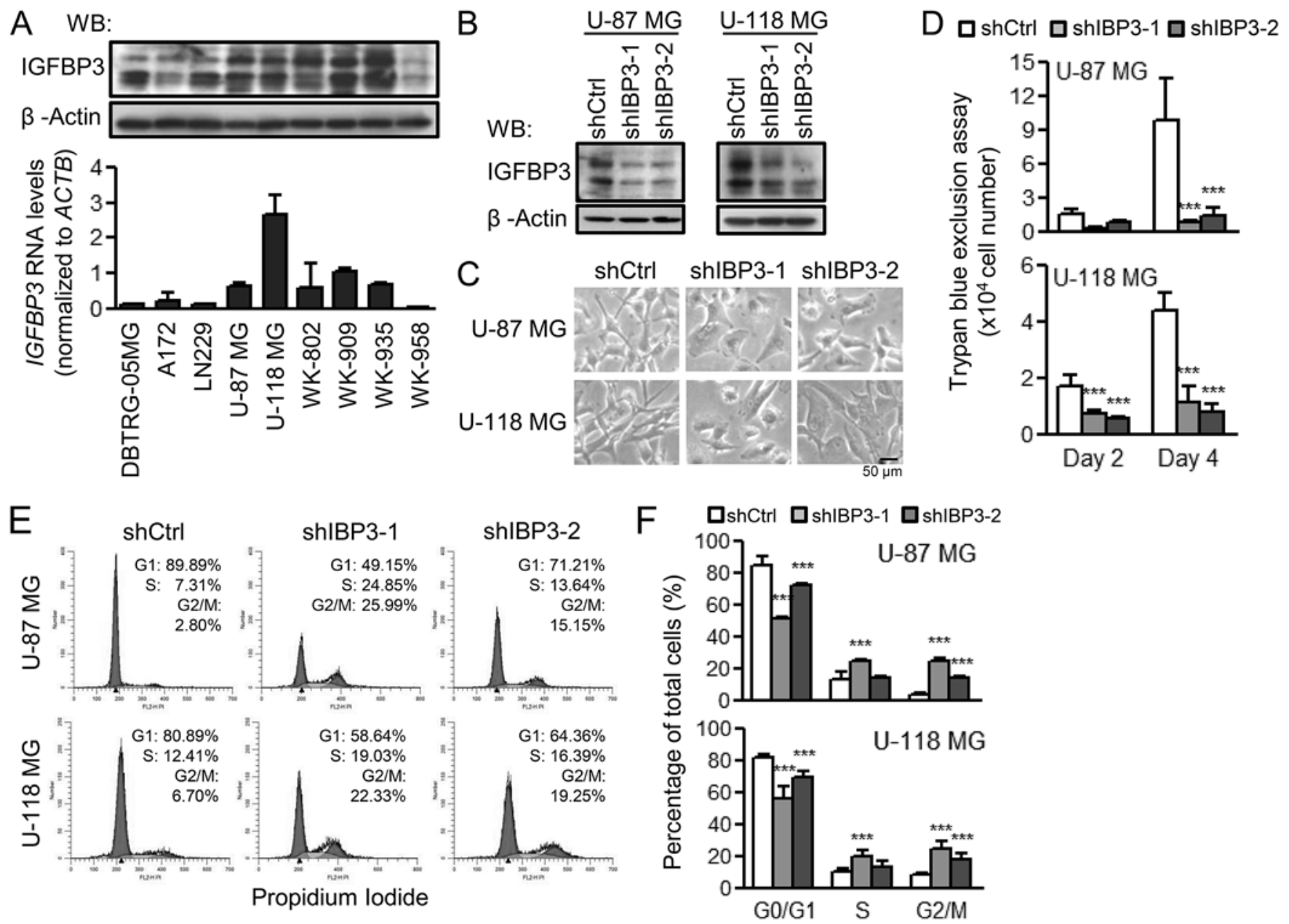

FIG. 3. IGFBP3 knockdown in glioma cells suppressed tumor cell proliferation. A: IGFBP3 expression in glioma cell lines and primary cells. B: IGFBP3 expression in the control vector (shCtrl) or IGFBP3 shRNA-expressing (shIBP3) cells. C: Morphological changes in IGFBP3 knockdown cells. D: Effect of IGFBP3 knockdown on cell proliferation by the trypan blue exclusion assay. Data represent the total number of cells per well. Effect of IGFBP3 knockdown on cell cycle distribution (E and F). E: Representative graphs showing cell cycle distribution. F: The statistical results of cell cycle distribution in control and IGFBP3 knockdown cells. ${ }^{*} p<0.05 ;{ }^{* *} p<0.01 ;{ }^{* * *} p<0.001$.

sidered important but difficult and the current treatments fail to control the progression of high-grade gliomas, ${ }^{26}$ identification of specific grouping markers and new drug targets will facilitate precision medicine and improve the treatment outcome of fetal GBM. ${ }^{10}$ Previous reports have shown that IGFBP3 is a multifunctional protein abundant in brain tumors; its expression is more upregulated in GBM than in low-grade gliomas and normal brains. ${ }^{22}$ Here we confirmed that IGFBP3 expression was upregulated in gliomas and further demonstrated a correlation between IGFBP3 and tumor grade, histology, and IDHI/2 mutations. Also, IGFBP3 has been known to regulate cell proliferation, differentiation, apoptosis, and angiogenesis in many cancers. ${ }^{2}$ We showed in glioma that IGFBP3 depletion suppresses tumor growth by inducing DSB accumulation and apoptosis and prolongs survival in braintumor-bearing mice. Our findings suggest that IGFBP3 expression is essential for glioma progression; therefore, depleting IGFBP3 expression represents a potential strategy for treating GBM.
In this study, we identified IGFBP3 as a grade-dependent prognostic factor that is up-regulated in glioma, with differential expression according to tumor histology and IDHI/2 status. We found that tumors derived from oligodendroglial cells including GBM proneural subgroups express lower levels of IGFBP3. Oligodendroglioma is characterized by carrying the $1 \mathrm{p} / 19 \mathrm{q}$ codeletion concurrent with the $I D H I$ mutation, ${ }^{20}$ and most GBMs bearing the IDHI mutation are grouped into the proneural subgroup. ${ }^{25}$ Our results are consistent with previous reports and further suggest that lower IGFBP3 expression is strongly correlated to oligodendroglial tumor phenotypes as well as IDH1/2 mutations. To actually define the clinical relevance of IGFBP3 in glioma, more effort must be made to confirm the relationship between IGFBP3 expression and current prognostic factors.

Although correlation of IGFBP3 expression to shorter overall survival in glioma patients suggests IGFBP3 as a prognostic factor in glioma, our results indicate tumor grade as the only independent prognostic factor in glioma. 


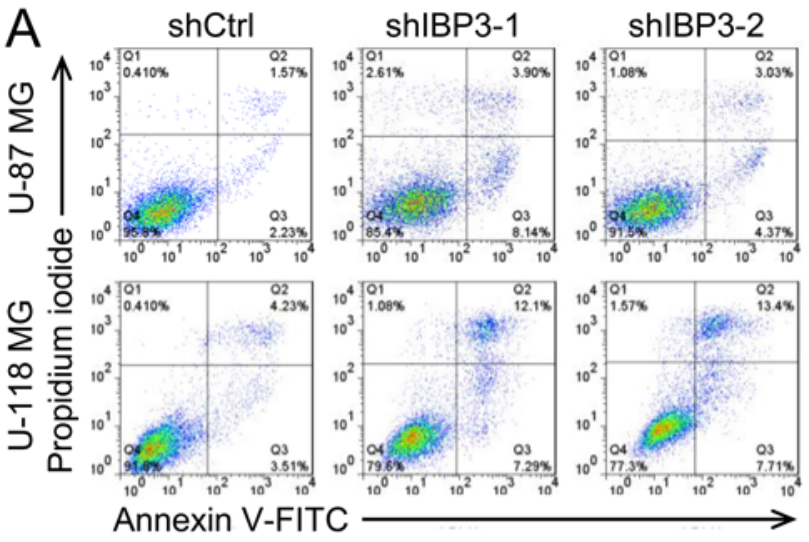

B
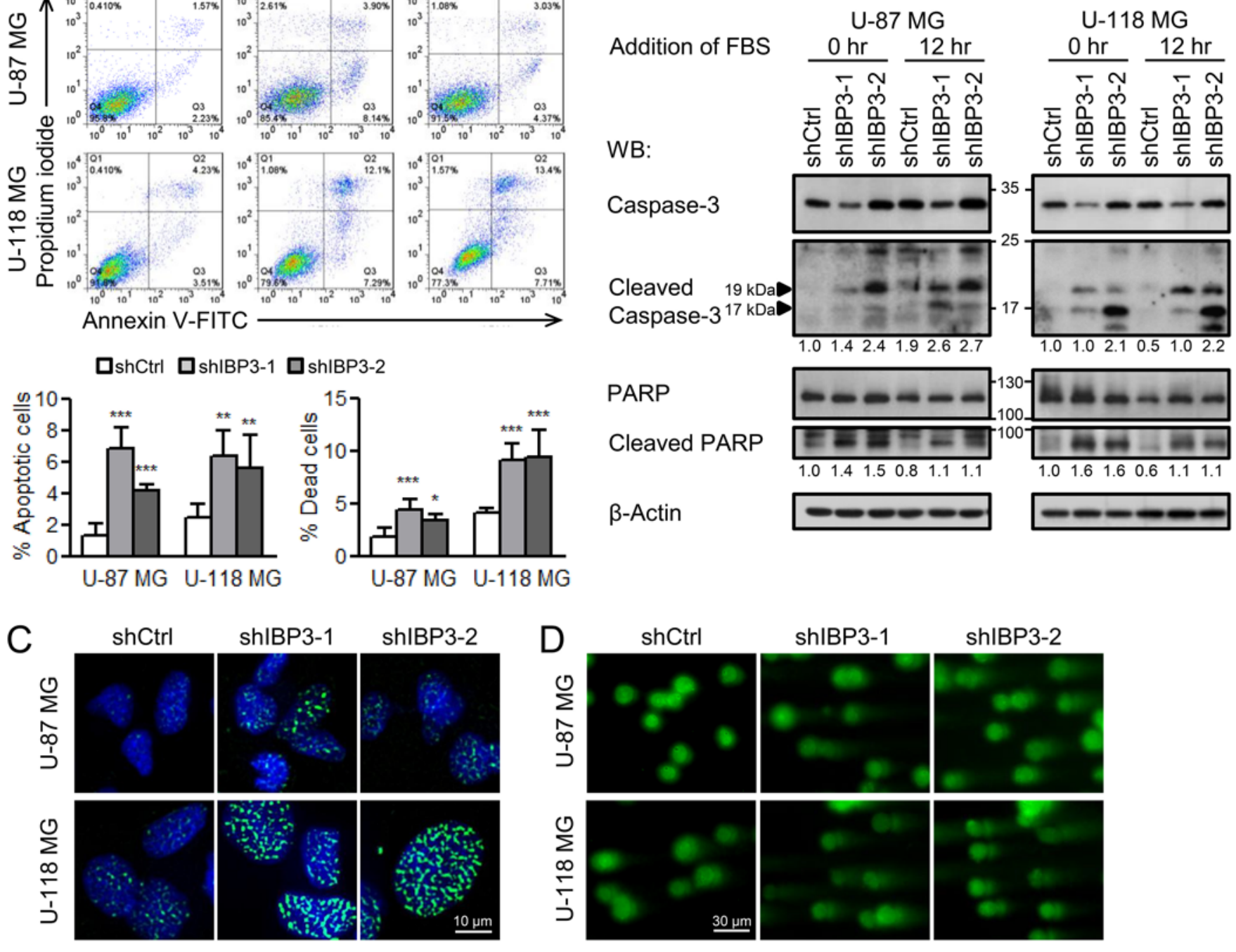

shIBP3-2
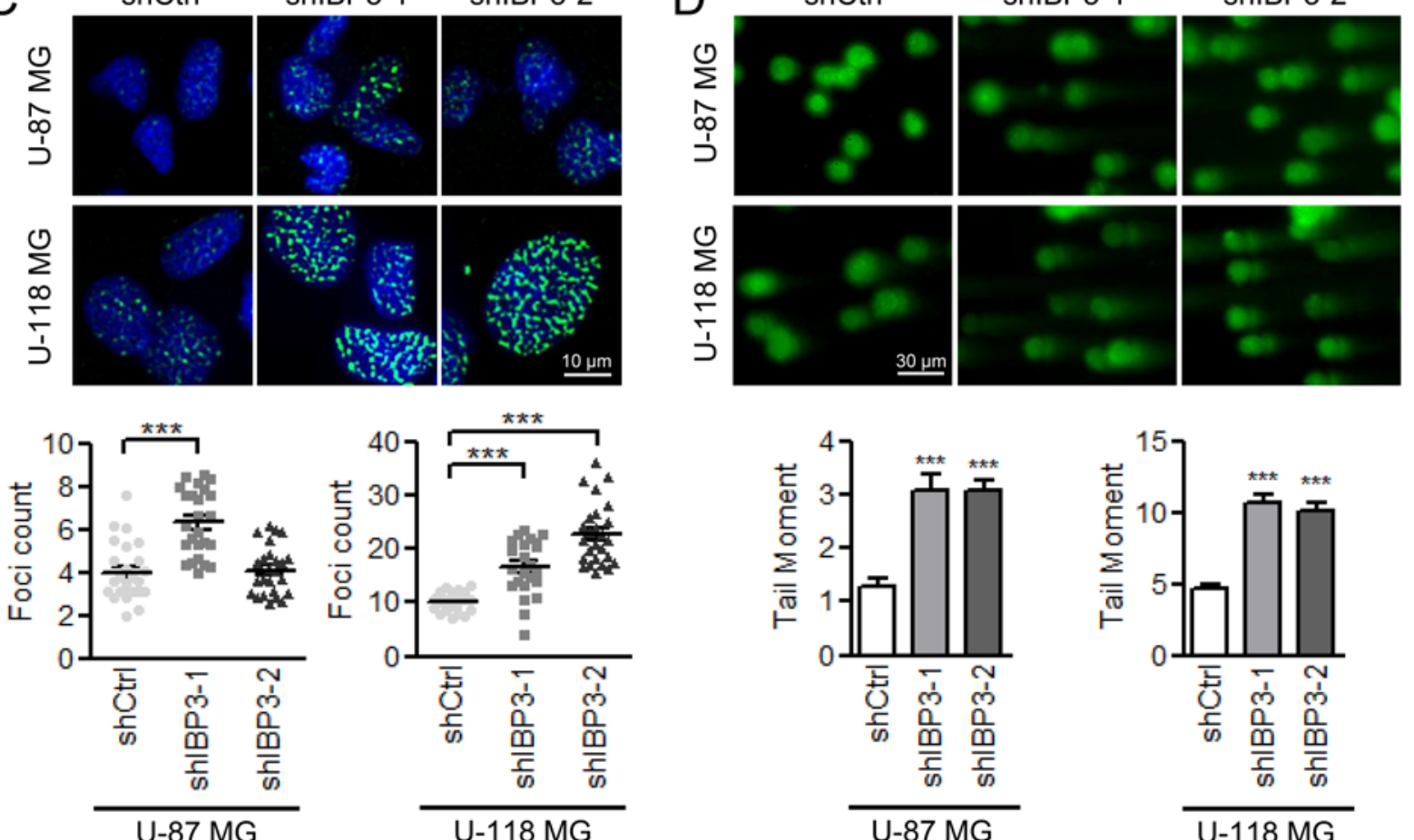

U-87 MG

$\mathrm{U}-118 \mathrm{MG}$
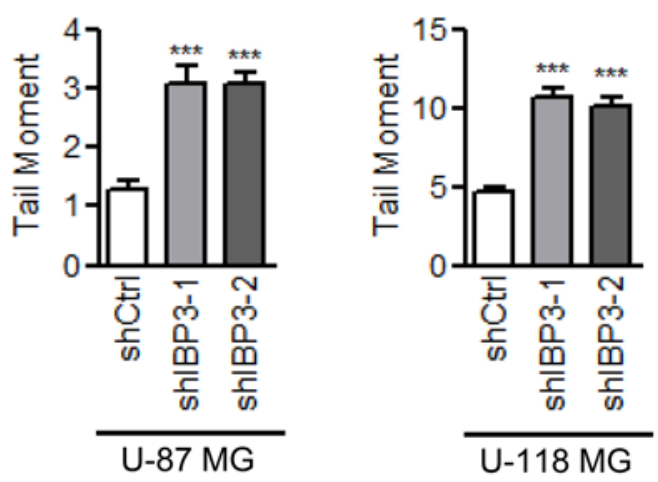

FIG. 4. IGFBP3 knockdown induced apoptosis and DNA damage in glioma cells. A and B: Effect of IGFBP3 knockdown on early cell apoptosis by annexin V-PI flow cytometry assays (A) and caspase-3 and PARP cleavage (B). Protein expression was normalized to $\beta$-actin and is presented as fold changes compared with that in shCtrl cells at 0 hours. C: Effect of IGFBP3 knockdown on DNA damage in glioma cells measured using the alkaline comet assay. D: Effect of IGFBP3 knockdown on $\gamma \mathrm{H} 2 \mathrm{AX}$ focus formation in glioma cells. Images of $\gamma \mathrm{H} 2 \mathrm{AX}$ foci (green) were taken using a confocal microscope. Cell nuclei (blue) were stained with DAPI. Data are presented as the number of foci per cell. ${ }^{*} p<0.05$; ${ }^{* *} p<0.01$; ${ }^{* * *} p<0.001$. 

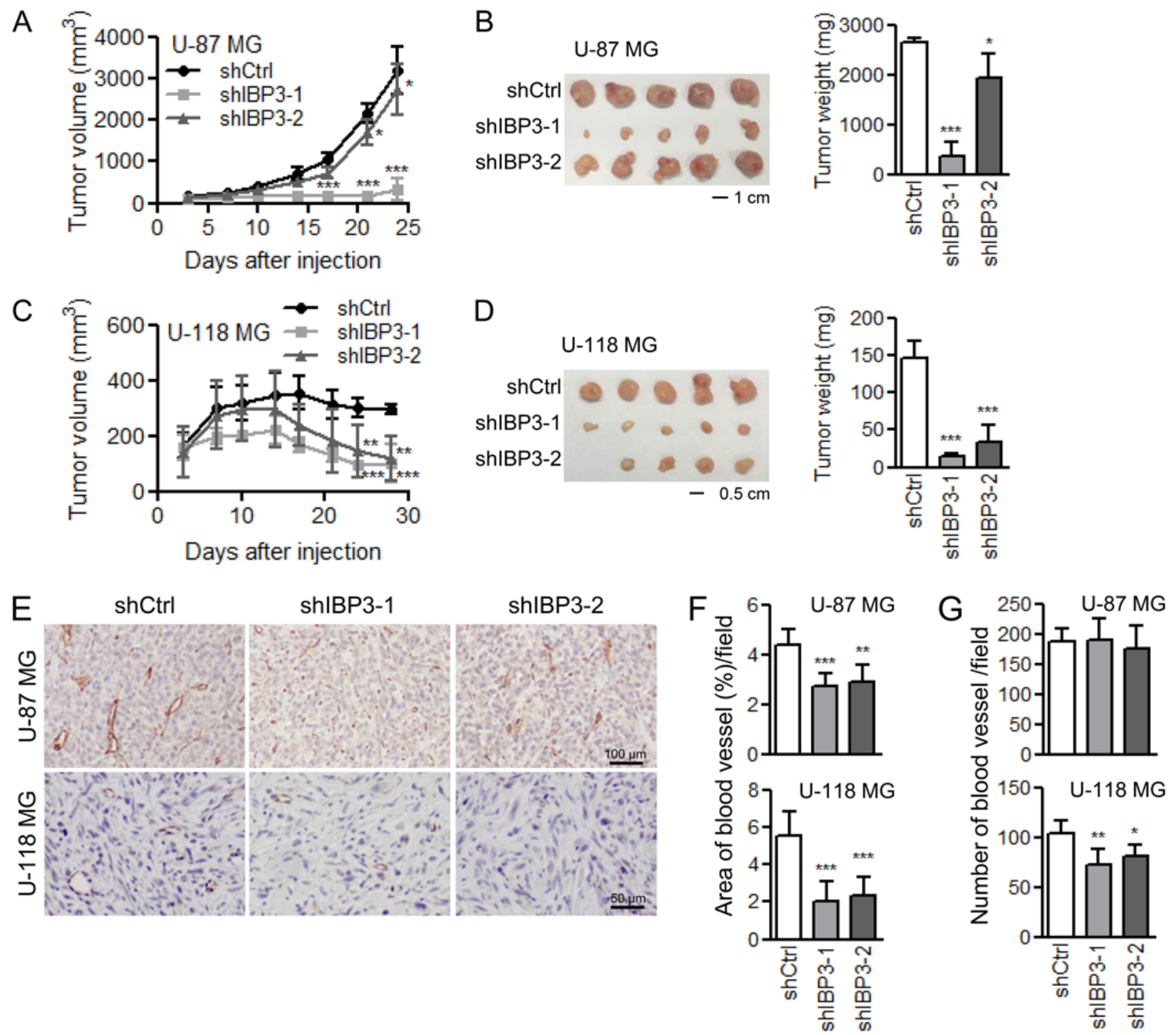

FIG. 5. Effect of IGFBP3 knockdown on in vivo growth of glioma cells using mouse subcutaneous xenograft models. U-87 MG ( $A$ and $B$ ) and $U-118$ MG (C and D) were subcutaneously injected into NOD-SCID mice ( $n=5$ for each group). A and C: Tumor growth curve shows the tumor size measured twice a week. B and D: Tumor images and weights of the removed subcutaneous tumors after inoculation for 24 (U-87 MG) or 28 (U-118 MG) days. E-G: Effect of IGFBP3 knockdown on blood vessels in mouse subcutaneous xenograft models. Representative images $(E)$ of blood vessels stained with an antibody against mouse CD31 in mouse subcutaneous tumors. The average blood vessel area $(F)$ and number $(G)$ were measured using ImageJ. ${ }^{*} p<0.05$; ${ }^{* *} p<0.01 ;{ }^{* *} p<0.001$.

IGFBP3 RNA expression levels may not be an optimal prognostic factor in GBM due to the minimally insignificant differences between IGFBP3 expression groups and high variation among different patient sources. Albeit with small sample sizes, lower IGFBP3 expression correlated with better overall survival of patients with proneural GBM, which is the subgroup most intractable to current therapy due to its lack of response to chemotherapy or radiotherapy. ${ }^{25}$ Together, these findings suggest that the heterogeneous nature of GBM may have contributed toward the nonsignificant correlation of IGFBP3 expression with
GBM patient survival. Further studies with larger sample sizes are required to further understand the clinical relevance of IGFBP3 expression in GBM.

IGFBP3 has multiple biological roles; this is implied by its distribution in multiple cellular compartments and interactions with various molecules, which in turn result in conflicting effects on cell growth among cancers. ${ }^{1,30}$ IGFBP3 has often been considered as a tumor suppressor that induces apoptosis via IGF-I-dependent and -independent signaling pathways. ${ }^{14,28}$ However, IGFBP3 can promote tumor growth by potentiating IGF-I-dependent 

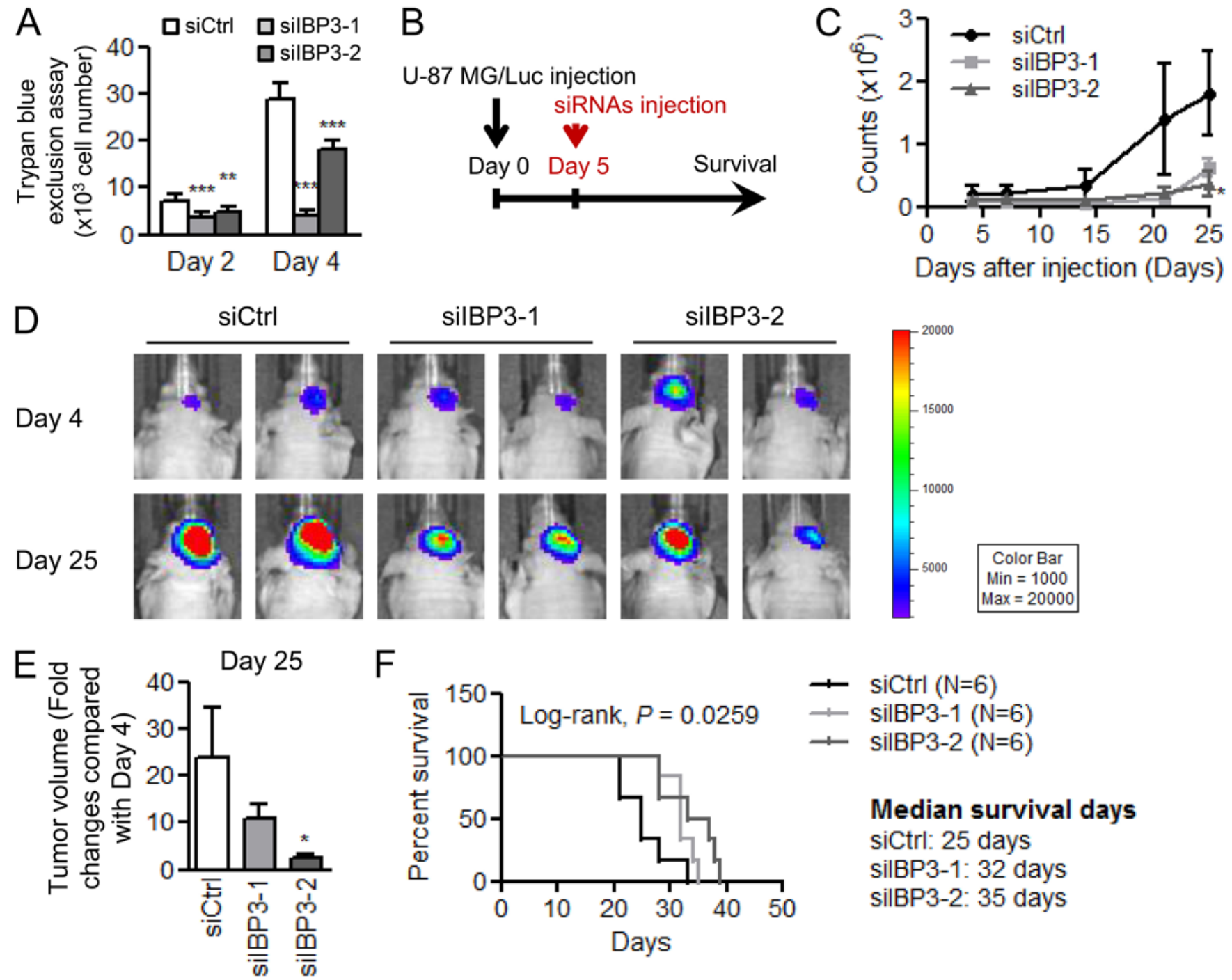

Median survival days sictrl: 25 days silBP3-1: 32 days silBP3-2: 35 days

FIG. 6. IGFBP3 siRNA suppressed tumor growth and prolonged mouse survival in mouse intracranial xenograft models. A: Effect of IGFBP3 siRNA on cell proliferation measured using the trypan blue exclusion assay. B: Time course of IGFBP3 siRNA treatment in the mouse intracranial U-87 MG/Luc xenograft model. C: Infusion of two different IGFBP3 siRNAs (silBP3-1 and silBP3-2) delayed tumor growth in the brains of the mice. Tumor growth curve measured by IVIS Spectrum. Data are presented as average bioluminescence intensity \pm SEM. D: Representative images of tumor bioluminescence intensity after U-87 MG/Luc inoculation after 4 and 25 days. E: Tumor volume at day 25 compared with that at day 4 . Data are presented as average fold changes of bioluminescence intensity at day 25 compared with day 4 . Error bars represent \pm SEM. F: Effect of IGFBP3 siRNAs on mouse survival $(n=6) . p=0.0259$, log-rank test. Median survival of each group was 25 days for siCtrl, 32 days for silBP3-1, and 35 days for silBP3-2. ${ }^{*} p<0.05 ;{ }^{* *} p<0.01 ;{ }^{* * *} p<0.001$.

proliferation and increasing S1P formation that transactivates other signaling pathways. ${ }^{6,16}$ Furthermore, IGFBP3 expression may sustain cell proliferation by enhancing IGF-I-induced DNA synthesis. ${ }^{11}$ IGFBP3 can also stimulate breast cancer cell survival under glucose starvation and promote esophageal cancer growth by suppressing oxidative stress. ${ }^{7,18}$ A previous study showed that IGFBP3 knockdown impaired the proliferation capability of U-251 MG glioma cells in vitro. ${ }^{24}$ Here, we performed IGFBP3 knockdown by expressing IGFBP3 siRNAs in five glioma cell lines and four GBM primary cell lines and confirmed a growth-suppressing effect of IGFBP3 depletion in vitro; we further suggested a tumor-growth suppression effect of
IGFBP3 siRNAs in in vivo intracranial xenograft mouse models. Our findings demonstrate that depleting IGFBP3 expression by IGFBP3 siRNA is a novel and promising targeted therapy in treating GBM patients.

By measuring DSBs in nuclei using $\gamma \mathrm{H} 2 \mathrm{AX}$ staining and comet assays, we demonstrated that IGFBP3 depletion induced DSB accumulation that results in growth arrest and apoptosis in tumor cells. Previous research has focused on the effects of IGFBP3 on stimuli-induced DNA damage but the results are conflicting. Overexpression of IGFBP3 increased apoptosis and radiosensitivity to ionizing radiation in breast cancer cells, ${ }^{4}$ and intracranially injected IGFBP3 suppressed tumor growth and sensitized 
tumors to doxorubicin in prostate cancer. ${ }^{9}$ On the contrary, IGFBP3 cotranslocates with EGFR to the nucleus and forms a complex with DNA-dependent protein kinase catalytic subunit (DNA-PKcs) in response to DSB-inducing chemotherapeutic agents. Therefore, IGFBP3 knockdown suppresses DNA repair activity. ${ }^{12}$ In our study, DNA DSBs were induced by depleting IGFBP3 expression, but the underlying molecular mechanisms are still unrevealed. One possible way is through controlling the formation of DNAPKcs-EGFR complex as previously reported, ${ }^{12}$ while other signaling molecules might also contribute to the regulation of DNA damage. Because it is a potential therapy in treating GBM, more effort must be made to clarify the underlying mechanisms of IGFBP3 depletion in DNA repair deficiency.

Overall, we report that IGFBP3 depletion suppresses tumor growth in vitro and in vivo by inducing DSB accumulation and cell apoptosis. Targeting IGFBP3 in vivo using IGFBP3 siRNA significantly prolonged the survival of brain-tumor-bearing mice. Thus, IGFBP3 expression modulation represents a potential GBM treatment by controlling tumor growth.

\section{Conclusions}

High-grade gliomas have long been considered untreatable and have little response to current therapies. Therefore, developing new therapies and increasing understanding of the tumor molecular pathogenesis are imperative. Previous studies have suggested IGFBP3 as a prognostic factor predicts poor outcome in GBM. We confirmed $I G F B P 3$ is upregulated in glioma and further correlated its expression with tumor histology and IDHI/2 mutations. Furthermore, we found that knockdown of IGFBP3 directly induced DNA DBSs and cell apoptosis, which resulted in suppression of tumor growth. In vivo treatment of intracranial tumors with IGFBP3 siRNAs successfully suppressed tumor growth and prolonged mouse survival. Here, we propose IGFBP3 depletion as a potential therapy for treating glioma through induction of DNA damage and apoptosis.

\section{Acknowledgments}

We thank the Brain Tumor Center (University of California, San Francisco, CA) for kindly providing U-87 MG/Luc cells. We thank the National RNAi Core Facility at Academia Sinica in Taiwan for providing shRNA reagents and related services. We thank Ms. ShiangTing Lin for her technical assistance in cell culture and experiments of molecular biology.

This work was supported by the Ministry of Science and Technology, ROC (grant numbers 105-2314-B-182-019-MY3, 105-2811-M-182-001, and 106-2811-M-182-013 to K.C. Wei and 105-2314-B-182-007 to P.Y. Chen); the National Health Research Institutes, Taiwan (grant number NHRI-EX106-10502NI to K.C. Wei); and the Chang Gung Memorial Hospital, Linkou Medical Center (grant numbers CMRPG3G1261 and CMRPG3D0483 to K.C. Wei).

\section{References}

1. Baxter RC: IGF binding proteins in cancer: mechanistic and clinical insights. Nat Rev Cancer 14:329-341, 2014

2. Baxter RC: Insulin-like growth factor binding protein-3
(IGFBP-3): novel ligands mediate unexpected functions. J Cell Commun Signal 7:179-189, 2013

3. Brennan CW, Verhaak RG, McKenna A, Campos B, Noushmehr H, Salama SR, et al: The somatic genomic landscape of glioblastoma. Cell 155:462-477, 2013

4. Butt AJ, Firth SM, King MA, Baxter RC: Insulin-like growth factor-binding protein-3 modulates expression of $\mathrm{Bax}$ and $\mathrm{Bcl}-2$ and potentiates $\mathrm{p} 53$-independent radiationinduced apoptosis in human breast cancer cells. J Biol Chem 275:39174-39181, 2000

5. Eckel-Passow JE, Lachance DH, Molinaro AM, Walsh KM, Decker PA, Sicotte H, et al: Glioma groups based on 1p/19q, IDH, and TERT promoter mutations in tumors. $\mathbf{N}$ Engl J Med 372:2499-2508, 2015

6. Granata R, Trovato L, Garbarino G, Taliano M, Ponti R, Sala G, et al: Dual effects of IGFBP-3 on endothelial cell apoptosis and survival: involvement of the sphingolipid signaling pathways. FASEB J 18:1456-1458, 2004

7. Grkovic S, O'Reilly VC, Han S, Hong M, Baxter RC, Firth SM: IGFBP-3 binds GRP78, stimulates autophagy and promotes the survival of breast cancer cells exposed to adverse microenvironments. Oncogene 32:2412-2420, 2013

8. Gusev Y, Bhuvaneshwar K, Song L, Zenklusen JC, Fine H, Madhavan S. The REMBRANDT study, a large collection of genomic data from brain cancer patients. Scientific Data 5:180158, 2018

9. Han J, Jogie-Brahim S, Harada A, Oh Y: Insulin-like growth factor-binding protein-3 suppresses tumor growth via activation of caspase-dependent apoptosis and cross-talk with NF$\kappa B$ signaling. Cancer Lett 307:200-210, 2011

10. Jue TR, McDonald KL: The challenges associated with molecular targeted therapies for glioblastoma. J Neurooncol 127:427-434, 2016

11. Leibowitz BJ, Cohick WS: Endogenous IGFBP-3 is required for both growth factor-stimulated cell proliferation and cytokine-induced apoptosis in mammary epithelial cells. J Cell Physiol 220:182-188, 2009

12. Lin MZ, Marzec KA, Martin JL, Baxter RC: The role of insulin-like growth factor binding protein-3 in the breast cancer cell response to DNA-damaging agents. Oncogene 33:85-96, 2014

13. Louis DN, Perry A, Reifenberger G, von Deimling A, Figarella-Branger D, Cavenee WK, et al: The 2016 World Health Organization Classification of Tumors of the Central Nervous System: a summary. Acta Neuropathol 131:803-820, 2016

14. Ma Y, Han CC, Li Y, Wang Y, Wei W: Insulin-like growth factor-binding protein-3 inhibits IGF-1-induced proliferation of human hepatocellular carcinoma cells by controlling bFGF and PDGF autocrine/paracrine loops. Biochem Biophys Res Commun 478:964-969, 2016

15. Marimuthu A, Chavan S, Sathe G, Sahasrabuddhe NA, Srikanth SM, Renuse S, et al: Identification of head and neck squamous cell carcinoma biomarker candidates through proteomic analysis of cancer cell secretome. Biochim Biophys Acta 1834:2308-2316, 2013

16. Martin JL, Lin MZ, McGowan EM, Baxter RC: Potentiation of growth factor signaling by insulin-like growth factor-binding protein-3 in breast epithelial cells requires sphingosine kinase activity. J Biol Chem 284:25542-25552, 2009

17. Marzec KA, Baxter RC, Martin JL: Targeting insulin-like growth factor binding protein-3 signaling in triple-negative breast cancer. BioMed Res Int 2015:638526, 2015

18. Natsuizaka M, Kinugasa H, Kagawa S, Whelan KA, Naganuma S, Subramanian H, et al: IGFBP3 promotes esophageal cancer growth by suppressing oxidative stress in hypoxic tumor microenvironment. Am J Cancer Res 4:29-41, 2014

19. Ostrom QT, Gittleman H, Liao P, Vecchione-Koval T, Wolinsky Y, Kruchko C, et al: CBTRUS Statistical Report: primary brain and other central nervous system tumors diagnosed 
in the United States in 2010-2014. Neuro Oncol 19 (Suppl 5):v1-v88, 2017

20. Ostrom QT, Gittleman H, Xu J, Kromer C, Wolinsky Y, Kruchko C, et al: CBTRUS Statistical Report: primary brain and other central nervous system tumors diagnosed in the United States in 2009-2013. Neuro Oncol 18 (Suppl 5):v1v75, 2016

21. Qazi MA, Vora P, Venugopal C, Sidhu SS, Moffat J, Swanton $\mathrm{C}$, et al: Intratumoral heterogeneity: pathways to treatment resistance and relapse in human glioblastoma. Ann Oncol 28:1448-1456, 2017

22. Santosh V, Arivazhagan A, Sreekanthreddy P, Srinivasan H, Thota B, Srividya MR, et al: Grade-specific expression of insulin-like growth factor-binding proteins-2, -3 , and -5 in astrocytomas: IGFBP-3 emerges as a strong predictor of survival in patients with newly diagnosed glioblastoma. Cancer Epidemiol Biomarkers Prev 19:1399-1408, 2010

23. Takahashi M, Papavero V, Yuhas J, Kort E, Kanayama HO, Kagawa S, et al: Altered expression of members of the IGFaxis in clear cell renal cell carcinoma. Int J Oncol 26:923931, 2005

24. Thota B, Arimappamagan A, Kandavel T, Shastry AH, Pandey P, Chandramouli BA, et al: STAT-1 expression is regulated by IGFBP-3 in malignant glioma cells and is a strong predictor of poor survival in patients with glioblastoma. $\mathbf{J}$ Neurosurg 121:374-383, 2014

25. Verhaak RG, Hoadley KA, Purdom E, Wang V, Qi Y, Wilkerson MD, et al: Integrated genomic analysis identifies clinically relevant subtypes of glioblastoma characterized by abnormalities in PDGFRA, IDH1, EGFR, and NF1. Cancer Cell 17:98-110, 2010

26. Wang H, Xu T, Jiang Y, Xu H, Yan Y, Fu D, et al: The challenges and the promise of molecular targeted therapy in malignant gliomas. Neoplasia 17:239-255, 2015

27. Wang HC, Pao J, Lin SY, Sheen LY: Molecular mechanisms of garlic-derived allyl sulfides in the inhibition of skin cancer progression. Ann N Y Acad Sci 1271:44-52, 2012

28. Wang YA, Sun Y, Palmer J, Solomides C, Huang LC, Shyr Y, et al: IGFBP3 modulates lung tumorigenesis and cell growth through IGF1 signaling. Mol Cancer Res 15:896-904, 2017
29. Xue A, Scarlett CJ, Jackson CJ, Allen BJ, Smith RC: Prognostic significance of growth factors and the urokinase-type plasminogen activator system in pancreatic ductal adenocarcinoma. Pancreas 36:160-167, 2008

30. Yamada PM, Lee KW: Perspectives in mammalian IGFBP-3 biology: local vs. systemic action. Am J Physiol Cell Physiol 296:C954-C976, 2009

31. Zeman MK, Cimprich KA: Causes and consequences of replication stress. Nat Cell Biol 16:2-9, 2014

\section{Disclosures}

The authors report no conflict of interest concerning the materials or methods used in this study or the findings specified in this paper.

\section{Author Contributions}

Conception and design: $\mathrm{CH}$ Chen. Acquisition of data: Wei, $\mathrm{CH}$ Chen, PY Chen, Feng, SH Chen, CY Chen. Analysis and interpretation of data: $\mathrm{CH}$ Chen, Lin, Jung, LY Chen. Drafting the article: $\mathrm{CH}$ Chen. Critically revising the article: $\mathrm{CH}$ Chen, Lin, YC Huang. Reviewed submitted version of manuscript: $\mathrm{CH}$ Chen, Lin, YC Huang. Statistical analysis: CH Chen, Lin. Administrative/technical/material support: Wei, PY Chen, CY Huang. Study supervision: Wei.

\section{Supplemental Information Online-Only Content}

Supplemental material is available with the online version of the article.

Supplementary Information. https://thejns.org/doi/suppl/10. 3171/2018.8.JNS181217.

\section{Correspondence}

Kuo-Chen Wei: Chang Gung Memorial Hospital, Linkou Medical Center, Taoyuan, Taiwan. kuochenwei@cgmh.org.tw. 